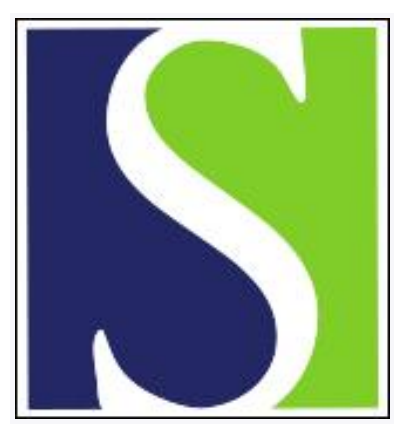

Scand J Work Environ Health 1995;21(4):245-251

https://doi.org/10.5271/sjweh.33

Issue date: Aug 1995

\title{
Ethical aspects of prevention
}

by Tomatis L

Key terms: human experimentation; informed consent; need for complete and correct information; privilege of prevention

This article in PubMed: www.ncbi.nlm.nih.gov/pubmed/8552997

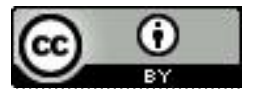




\title{
Ethical aspects of prevention
}

\author{
by Lorenzo Tomatis, $M D^{1}$
}

\begin{abstract}
Tomatis L. Ethical aspects of prevention. Scand J Work Environ Health 1995;21:245-51.
Within the very large area of ethical concerns, the following issues are considered in this paper: (i) intellectual and career-oriented ambition, combined with the pressure that the competition for funds exerts, may push certain scientists to make dubious compromises with their conscience; (ii) exaggerated priority is sometimes given to the smooth running of a trial, even at the cost of ignoring some ethical requirements; (iii) it is questionable whether preventive intervention can adequately and systematically replace primary prevention based on the cessation of exposure to carcinogens; (iv) it is of the utmost importance to ensure that preventive treatment that is to be administered for long periods has no adverse effects or that the benefits by far outweigh the possible risks; (v) the informed consent of participants to the trials is essential and it should be obtained on the basis of correct, complete and clear information; (vi) a different type of informed consent is that of all citizens with regard to risks to which they may be exposed voluntarily or involuntarily; (vii) there is no justification for, and it is profoundly unethical to omit, delay, or hide information that may be relevant to the protection of health. Four examples were chosen to illustrate the preceding points.
\end{abstract}

Key terms human experimentation, informed consent, need for complete and correct information, privileges of prevention.

\section{Two aspects of medicine}

The ethical aspects of medicine and of clinical research have been discussed from the time of Hippocrates. For centuries thereafter the main attitude was to respect certain fundamental rules of behavior, which were rather simple but nevertheless inconsistently observed: generosity, compassion, dedication, disinterestedness (1).

Thomas Percival in England in 1803, William Beaumont in the United States in 1833, and Claude Bernard in France in 1865 wrote extensively about the ethics of medical practice and of experimental medicine. They stressed the obligation of always assigning priority to the scientific validity of a planned experiment and the necessity that the experiment include benefit for the person involved (2). As was stressed many years later, what is not scientific is of itself unethical, but all that is scientific is not necessarily ethical (1).

Medicine as a science, like other sciences, aims above all at acquiring and expanding knowledge, while medicine as health care and cure has the people's protection and welfare as its primary goal (3). These two aspects of medicine very often coexist. Although one may prevail in some situations, there should never be a complete prevalence of the cognitive aspect when the direct health care of patients is involved.

When the care of a patient includes a component of research that has no immediate beneficial fall-out, not only must it not represent a risk for the patient, but it must also have as its goal benefit for future patients. In other words, no activity should be initiated within biomedical research with the sole purpose of satisfying intellectual curiosity or extending knowledge, unless the final goal is to contribute to recovery from a disease, or to mitigate or prevent damage of disease.

The ethical choice of attributing an absolute value to a person is a fundamental axiom of medicine, indispensable for defining the concepts of health and disease that would otherwise escape any definition made on purely objective grounds. Having an ethical value as its foundation makes medicine an atypical science.

\section{Regulations of human experimentation}

The first official regulation of human experimentation was a circular from the Ministry of Religious Affairs,

\section{3 , Chemin de Grandvaux, 69130 Ecully, France.}

Reprint requests to: Dr Lorenzo Tomatis, 53, Chemin de Grandvaux, 69130 Ecully, France. 
Education and Medicine of Prussia, on 29 December 1900. The regulation was motivated by the Neisser case. Alfred Neisser, a scientist well known for having discovered, in 1879, the bacterium that causes gonorrhea, had inoculated uninformed and nonconsenting adolescents with serum from luetic patients to test a possible immunization against syphilis. As a result, all of the adolescents developed syphilis. The ministerial circular prescribed that human experimentation must not be performed on minors, disabled persons, or any individuals who had not unequivocally declared their consent (2).

On 28 February 1931, again in Germany, the Ministry of the Interior issued a circular providing guidance for innovative therapy and scientific experimentation. At the origin of this ministerial action was another tragic episode of human experimentation: an attempt to develop a vaccine against tuberculosis that caused the deaths of 75 children in Lübeck. The guidance covered almost all of the issues that later appeared in the Nuremberg Code of 1945, a demonstration, among other things, of the minimal relevance of a legal regulation when its rigorous application is not guaranteed by authorities (4).

In chronological order, after the circulars of 1900 in Prussia and of 1931 in Germany, guidelines on the specific subject of human experimentation were elaborated at the Doctor's Trial in Nuremberg, by the American Medical Association in 1946, and by the successive declarations of the World Medical Association: Helsinki I (1964), Helsinki II (1975), Helsinki III (1983), Helsinki IV (1989). The obligation to have informed consent from every individual participating in an experiment was clearly spelled out in the Prussian directive of 1900 and the German one of 1931. In the Nuremberg Code, consisting of 10 points formulated on the occasion of the final judgment of the "Doctor's Trial," with the purpose of regulating human experimentation, voluntary consent of each participant is the first article and is described "as absolutely essential."

In the Declaration of Helsinki of 1964 (Helsinki I) the necessity for having free consent does not appear in the first article. It is instead specified that in the case of clinical research combined with professional care the consent of the patient must be obtained "if at all possible." It is also specified, however, that nontherapeutic clinical research cannot be carried out without the full written consent of each participant. In the successive elaborations of the Helsinki declaration, in 1975, 1983, and 1989, the necessity for informed consent appears in point 9, and it is specified that it should be obtained "preferably in writing."

Now I would like to discuss the following two situations: (i) controlled clinical trials, including intervention studies, and (ii) the identification of cancer risk factors that lead to preventive intervention. The two situations have some points in common with regard to the level and quality of information to which every individual has a right. A long distance and considerable differences obviously separate these two situations from the extreme cases of human experimentation in which human subjects were treated with particular systematic cruelty, as in those judged at Nuremberg.

It is of some relevance, however, that national and international regulations on human experimentation were established (with the exception, ironically, being that of Germany) only after the Nuremberg trial. One of the principal experts at the "Doctor's Trial" in Nuremberg, the physiologist Andrew Ivy from Chicago, stated in his testimony that ethical principles on medical research were in force in the United States and had been adopted by the American Medical Association. As a matter of fact, in the United States, as in most other countries, official guidance on ethical principles regulating human experimentation did not exist before 1946. Most likely Andrew Ivy was referring, in perfectly good faith, to an absolutely valid, but not official ethical code, which he and most of his colleagues in the United States and in the rest of the world followed regularly and to which they were convinced it was natural to conform (2).

\section{Issues of ethical concern}

Within the very large area of ethical concerns I have arbitrarily selected a few issues that may need particular consideration: (i) intellectual and career-oriented ambition, combined with the pressure that the competition for funds exerts, may push certain scientists to make dubious compromises with their conscience; (ii) exaggerated priority is sometimes given to the smooth running of a trial, even at the cost of ignoring some ethical requirements; (iii) it is questionable whether preventive intervention can adequately and systematically replace primary prevention based on the cessation of exposure to carcinogens; (iv) it is of the utmost importance to ensure that preventive treatment that is to be administered for long periods has no short-, medium-, or long-term adverse effects or that the benefits by far outweigh the possible risks; ( $v$ ) informed consent of participants to the trials is essential and it should be obtained on the basis of correct, complete and clear information; (vi) a different type of informed consent is that of all citizens with regard to the risks to which they may be exposed voluntarily or involuntarily; and (vii) there is no justification for, and it is profoundly unethical to omit, delay or hide information that may be relevant to the protection of human health. I have chosen four examples to illustrate these points. 


\section{Controlled comparison of two types of intervention}

The National Surgical Adjuvant Breast and Bowel Project (NSABP) is, with respect to its declared objectives and the number of patients and collaborations, both within and outside the United States, one of the most important trials ever initiated. One of its objectives is to compare the efficacy of total mastectomy with that of limited nonmutilating intervention in early mammary cancers. A publication at the end of the $1970 \mathrm{~s}$ giving the first results of this trial provided evidence that limited surgical intervention is as effective as the more widely used mutilating intervention (5). The choice of treatment has since been considerably influenced by these results. Results obtained later within the same study (6) confirmed the original conclusions, which were supported by observations made elsewhere. All of the premises were therefore assembled so that this trial could be seen as a clear, convincing example of the usefulness of a controlled comparison of two types of intervention, with the beneficial result of avoiding severe mutilation without jeopardizing the favorable outcome of treatment.

In March, 1994, the daily Chicago Tribune reported that part of the data evaluated in the trial had been falsified $(7,8)$. Fortunately an additional analysis and rigorous evaluation of all the data were reported to indicate that the results of the 1970s and 1980s remained substantially valid, confirming that limited intervention is as effective as total mastectomy in the case of early mammary cancers (9). It was unfortunate, however, that the publication of the final analysis of the whole of the data was somewhat delayed (10).

Even if the participants in the trial could be assured, the episode remains worrying. It would be hard to establish what pushed a Canadian doctor to alter his case series and manipulate the data he submitted to the trial coordinator. Although it is not for us to judge a person's behavior, it must be recognized that the pressure to which scientists are subjected in the competition for funds can be very stressful. Combined with a variable input of personal ambition and career prospects, it can be sufficiently strong to push emotionally and morally fragile persons towards extreme solutions.

Another side of the episode that raises some concern is that the falsification of the data exposed by the Chicago Tribune reporter had been known for some time by the scientists responsible for the trial. They had chosen not to reveal the fact that some of the data had been falsified to avoid a scandal that could have endangered the course and funding of the trial.

Problems are not unusual in the management of clinical trials, however. An investigation carried out by the Federal Drug Administration between 1971 and 1994 on over 3000 trials ongoing in the United States identified deficiencies in the questionnaires to obtain informed consent in $56 \%$ of the cases, nonstrict adherence to the agreed protocol in $29 \%$, and inaccuracies in the registers in $23 \%$ of the cases $(11,12)$.

\section{Preventive intervention among smokers}

The example that follows concerns an intervention study to prevent or delay cancers of the lung and other sites in smokers. The study involved 29000 smokers, half of whom received beta-carotene and alpha-tocopherol (vitamin E), alone or in combination. The justification for this intervention was consistent epidemiologic evidence that the regular and abundant consumption of fruits and vegetables has a protective effect against the risks for cancer at several sites. (See reference 13 for a review.) The results at the end of six years of experimentation indicated that vitamin $\mathrm{E}$ had no effect and that betacarotene slightly increased the risk or accelerated the clinical appearance of tumors. Furthermore, the two treatments had no effect on mortality from cardiovascular disease (14).

The results of the study do not definitively exclude the possibility that beta-carotene and vitamin $\mathrm{E}$, alone or in combination, could exert a protective effect at different doses, after longer periods of administration or in respect to other variables. The dose of beta-carotene used was however relatively high, even causing coloring of the skin in one-third of the participants (15). The disappointing outcome of the study is a warning that the experimental design must include a careful and critical evaluation of variables that may influence effectiveness. Among these are duration, levels of exposure, the possible latency period necessary to verify an effect, possible contamination by other exposures, and the size of the population considered (16). The most important requirement, however, in the planning of trials is probably a deep(er) understanding of the mechanisms of actions of the compounds employed.

This study emphasized active intervention during the continuation of exposure to a carcinogenic mixture, even though there is no doubt that the most effective intervention for the subjects of the study would have been to interrupt their exposure to tobacco smoke. As the scientists did actually try to persuade each participant to give up smoking before inclusion in the study, the individuals who were enrolled in the trial could be considered incorrigible smokers. One might ask, however, whether greater success would have been achieved if the same means and personnel used during the six years of the study had been put instead into passive prevention. Many intervention studies are currently underway or are being planned in several countries (17). The possibility of contrasting or decreasing the effects of carcinogenic agents to which 
people are exposed constantly or frequently is very attractive, and it incites understandable, although at times perhaps even excessive, enthusiasm (18). It should not, however, lead to dismissal of the fact that avoiding exposure to known carcinogens is the first and in many instances the most important or only form of prevention.

\section{Prevention of mammary cancer by Tamoxifen}

A third example concerns the use of the drug Tamoxifen [(Z)-2-\{4-(1,2-diphenyl-1-butenyl)phenoxy\}-N,Ndimethylethanamine] an adjuvant in the treatment of mammary cancer, for active primary prevention. Tamoxifen is a very useful, effective drug in therapy, and several observations seemed to indicate that it could not only prevent relapses, but also decrease the risk of contralateral tumors $(19,20)$. Tamoxifen is also described as having a protective effect against ischemic heart disease and osteoporosis, but it is not without unwanted side effects. The most important of these is that it increases the risk for endometrial cancer, and it also increases the risk for thrombosis and, more rarely, retinopathy. To these proved side-effects should be added experimental evidence of its capacity to induce malignant liver tumors, even at relatively low doses.

Mammary cancer is the most common tumor in women, only part of the cases can be cured, and its etiology is not sufficiently understood to allow an efficient prevention program. At present only secondary prevention based on mass screening of women over 50 years of age and treatment, which is more efficacious during earlier stages of the disease, offer the possibility of decreasing the still rather high mortality from this tumor. It is evident, therefore, that the possibility of intervening before the disease is diagnosed exerts a great attraction and stimulates much hope.

Given the purpose of preventing a particularly frequent malignant tumor, the question was "Was it justified to test the capacity of Tamoxifen to prevent mammary cancer not only in women at high risk, but also in the general female population?" Since the main known risk factors are familial predisposition and age, a decision had to be made as to whether it was justified to recruit into the trial young women and women with no familial history of cancer, knowing that the drug, generally given therapeutically for two to five years, had to be administered for several decades in the trial (19-21). Different attitudes were seen in the United States and the United Kingdom, the two countries where the first studies began. In the United States the attitude to include in the trial young women and women without family history of cancer seemed to prevail, while the attitude that has officially appeared in the United Kingdom thus far has been a more cautious tendency to limit the trial to women at particularly high risk. In a study in Italy, increased risk for endometrial cancer has been avoided in the most drastic way, by enrolling only hysterectomized women (22).

After inception of the clinical trial, evidence emerged that the risk for endometrial cancer was higher than what was originally estimated and communicated to the participants of the trial before their consent was asked for (23). This information was not given immediately to the women involved in the trial, although it would seem logical that any new information that might change the elements on which consent is based should be released without delay. Another piece of information was also not given; it concerned experimental evidence of carcinogenicity, as discussed later.

The Tamoxifen case shows the difficulties, the limits, and the possible conflicts in the correct use of informed consent. On one hand the person who supplies the information may not be able to communicate it in an understandable way or may purposely omit some important details because they are considered too difficult for nonexperts to understand, such as certain scientific uncertainties and possible doubts. On the other hand, patients are usually capable of grasping the terms of the problem, but may be unable to understand some technical details or the differential relevance of certain data, including statistical evaluations of levels of risk.

The experimental evidence on the carcinogenicity of Tamoxifen deserves special comment. It has been known for years within the scientific environment that the company that produces Tamoxifen had carried out a longterm experiment that provided evidence that the drug is carcinogenic. Although solicited from many sides, the company did not make its data public nor did it publish them. At the end of 1992 the prepublication results of another study carried out in the United States began to circulate. These results confirmed the carcinogenicity of Tamoxifen; they were published in their final form in a peer-reviewed journal in 1993 (24). Not much later the data of the company producing Tamoxifen were published also (25). Further studies have shown that Tamoxifen is carcinogenic also after rather short periods of exposure and that it induces DNA (deoxyribonucleic acid) adducts which persist for a long time (26). Publication of the results obtained in the United States seemed therefore to have been instrumental in unblocking a deplorable situation. Some doubt might be cast, however, on the limpid unselfishness of the first publication. The laboratory that produced them was also testing, on behalf of a pharmaceutical company in competition with that producing Tamoxifen, an analogue of Tamoxifen with similar biological activities but apparently no carcinogenic effects (27). Tamoxifen was openly stated as being carcinogenic in a paper published a year later by another drug company producing another analogue of Tamoxifen (28). 


\section{Primary prevention and the right to information}

The fourth example concerns the general problem of primary prevention and the right of everyone to be informed exhaustively and correctly about the risks to health that may derive from exposure to noxious agents present in the environment. The first requirement in this respect is that such information exists, or that all efforts be made to obtain it, and that once obtained its accessibility be guaranteed. In this context, it is pertinent to quote the program of the International Agency for Research on Cancer (IARC) for the evaluation of carcinogenic risks to humans and its monograph series (29). The program, since its inception, has used all available data on a substance, including those on its chemical characteristics, its production, its presence in the environment, its uses, and, most importantly, biological and epidemiologic data. An evaluation of the risks that could derive from exposure to a particular environmental agent is then formulated on the basis of a rigorous critical analysis of the data.

In keeping with the criterion of correct, open information, evaluations are formulated in such a way as to allow the reader to follow the reasoning that led to it. In keeping with the same criterion, access to the original sources of information is always guaranteed to the reader. This guarantee requires that the data on which the evaluation is based be published or in any case be easily and universally available. In keeping with the principle of openly available information, IARC has therefore refused to consider data and information covered by clauses of confidentiality and secrecy.

Commercial and corporation laboratories justify the confidentiality and secrecy of some of their results by claiming the necessity of protection from possible competitors who could otherwise take advantage of the results without having had to make the considerable investment in time and money made to obtain them. Although it is understandable that drug companies and the chemical industry wish to be protected in their hard commercial struggle, this protection should not apply to results that prove serious toxicity and therefore point to a potential risk to humans. In other words, evidence of carcinogenicity is incompatible with a protectionist regime of confidentiality that would prevent dissemination of exhaustive, correct information.

In reality, the information given to the general public is often distorted and confused by tendentious publicity. Examples are the mystifying publicity disseminated by the tobacco multinationals ( 30 ) and by the corporations that produce and use asbestos (31), and, in the past, the deliberate omissions of data about the risks of occupational exposure to carcinogens, such as aromatic amines or bis-chloromethylether (32).

\section{Concluding remarks on the four examples}

Most of the arguments given in some detail in the preceding pages can be summarized in two statements: (i) improvements in diagnostic, therapeutic, and preventive methods require a quota for human experimentation (a crude term for describing clinical research and controlled clinical trials); (ii) no activity should be undertaken within biomedical research that aims at extending knowledge without also being useful for preventing, healing, or mitigating disease.

Between these two statements there is space for other thoughts. By accepting the principle that a quota on human experimentation is necessary, we enter a territory where biomedical action is not principally or exclusively centered on the immediate benefit of the patient. In the experimentation represented by controlled clinical trials, exhaustive, clear, correct information is an essential component. Some of the described examples indicate that this has not always been the case, even quite recently. They also show that some scientists, carried away by ambition or shaken by the pressure to which they are subjected by the merciless system of assigning funds, may be pushed into dealing with patients as though they were mere statistical entities rather than human beings.

With regard to scientific results that are relevant to the protection of human health, there is no possible justification (certainly not the protection of commercial interests) for hiding, delaying, omitting or distorting them. Access to all information that permits satisfaction of a right as fundamental as the right of health (33) must be guaranteed. Finally, notwithstanding the great hopes for primary prevention that could derive from active intervention to prevent the initiation of or to delay or stop the carcinogenesis process, it must not be forgotten that the avoidance of a maximal decrease in exposure to carcinogenic agents is still of fundamental importance in cancer prevention.

\section{A conflict of views}

There may be a conflict of views about the possible sacrifice of the strictly scientific approach to precautionary action or to the sacrifice of a precautionary action in order to remain strictly scientific (34). The desire to be strictly scientific does not necessarily mean to operate only in a way that allows public health decisions to be taken on the basis of all the available scientific evidence and methods, an attitude with which most of us will agree. Not rarely, it actually means continued experimentation in the search of answers and explanations that the available scientific evidence and methods do not permit and, in doing so, a delay in all precautionary action. 
A pertinent example of such a conflict is the opposite views with regard to the risks for health from air pollution according to environmentalists, ecologists, and many concerned scientists and those according to most health authorities and several well-known scientists. The available epidemiologic evidence consistently indicates that even common levels of air pollution, much lower than the highest levels observed on certain days, are associated with acute adverse health effects. There is also growing evidence of chronic respiratory effects (3539). Public health action is not taken because more credit is officially given to a skepticism that finds its scientific justification in an alleged lack of biological plausibility. Laboratory studies do not seem to confirm the epidemiologic evidence that adverse effects are produced by low levels of pollutants. Some people must have forgotten that there was a time when laboratory studies were unable to confirm the epidemiologic evidence of the carcinogenicity of tobacco smoke and would still today have great difficulty in confirming the epidemiologic evidence for the risks of passive smoking.

\section{The privileges of prevention}

Health expenditures account for a considerable and increasing proportion of the gross national product in industrialized countries $(40-42)$. This increase has not resulted in a proportionate gain in public health. The following three main reasons may possibly offer explanations: (i) no more than $2-3 \%$ of the budget for health is usually earmarked for prevention, (ii) it is generally the segment of the population that most needs it that has the least access to health care, and (iii) investment in health has been seen too often in terms similar to other sectors of the economy and has been conditioned by the same imperative of profit that drives most industries and private enterprises.

Prevention has two main ethical privileges related to its anticipatory virtue. The first is its intervention with the purpose of avoiding damage to health, and the second is its universality, that is, its intrinsic characteristics of protecting all individuals without the potential for discrimination on socioeconomic grounds that diagnostic and therapeutic approaches are likely to introduce. The fact that individuals are born in particular situations within society is, according to Rawls, neither just or unjust, as the distribution of natural talents is not just or unjust (43). These can be seen as natural facts that escape individual choices or collective decisions. What is just or unjust is the way institutions deal with these facts. The ethics of health should start from this point.

Expenditures in cancer research have increased considerably in the second part of this century. For instance the budget of the National Cancer Institute in the United States has grown from about 200 million dollars in 1969 to 1 billion in 1979 and to 2 billion in 1992 (44). In spite of the successes obtained in several areas, during the last two decades cancer mortality appears to have decreased only for certain tumors, while the incidence of many tumors is actually increasing (44). Today's situation seems therefore to confirm that insufficient priority has been given to prevention. Besides the two ethical privileges already mentioned, primary prevention has the additional double privilege of reducing human suffering while possibly also reducing health expenditures.

\section{Acknowledgments}

I wish to thank Ms E Heseltine for editing the manuscript.

\section{References}

1. Bernard J. La Bioéthique. Paris: Flammarion, 1994.

2. Grodin, MA. Historical origin of the Nuremberg Code. In: Annas GJ, Grodin MA, editors. The Nazi doctors and the Nuremberg Code. New York (NY): Oxford University Press, 1992:121-44.

3. Lauriola P, Cislaghi C, Botti C, Magnani C, Satolli R, Vineis P. Note preliminar i per la definizione di acune linee guida di etica in epidemiologia ambientale [Some preliminary remarks on ethical guidelines for environmental epidemiology]. Epidemiol Prevenzione 1994;18:184-7.

4. Perley S, Fluss SS, Bankowski Z, Simon F. The Nuremberg Code: an international overview. In: Annas GJ, Grodin MA, editors. The Nazi doctors and the Nuremberg Code. New York (NY): Oxford University Press, 1992:149-73.

5. Fisher B, Montague E, Redmond C, Barton B, Borland D, Fisher ER, et al. Comparison of radical mastectomy with alternative treatments for primary breast cancer: a first report of results from a prospective randomized clinical trial. Cancer 1977;39:2827-39.

6. Fisher B, Redmond C, Poisson R, Margolese R, Wolmark N, Wickerman L, et al. Eight-year results of a randomized clinical trial comparing total mastectomy and lumpectomy with or without irradiation in the treatment of breast cancer. N Engl J Med 1989;320:822-8.

7. Gavaghan H. Cancer institute to tighten control trials. Nature 1994: 368:679.

8. Anderson C. How not to publicize a misconduct finding. Science 1994;263:1679.

9. Sondik E. Reanalysis of NSABP studies. JNCI 1994;86:655.

10. Marshall E. Fisher clashes with NCI - again. Science 1995; 267:954.

11. Cohen J. Clinical trial monitoring: hit or miss. Science 1994:264:1534-7.

12. Nowack R. Problems in clinical trials go far beyond misconduct. Science 1994;264:1538-41.

13. Riboli E. Nutrition and cancer: background and rationale of 
the European prospective investigation into cancer and nutrition (EPIC). Ann Oncol 1992;3:783-91.

14. The alpha-Tocopherol, beta-Carotene Cancer Prevention Study Group. The effect of vitamin $\mathrm{E}$ and beta-carotene on the incidence of lung cancer and other cancers in male smokers. New Engl J Med 1994;330:1080 - 1.

15. Henneken $\mathrm{CH}$, Buring JE, Peto R. Antioxidant vitamins benefits not yet proved. New Engl J Med 1994;330:1080-1.

16. Susser M. Editorial: the tribulations of trials - intervention in communities. Am J Public Health 1995;85:156-8

17. Buiatti $E$. Intervention trials of cancer prevention: results and research programmes. Lyon: International Agency for Research on Cancer (IARC), 1994. IARC technical report, no 18.

18. Grenwald P, Kelloff $G$, Burch-Whitman C, Kramer BS. Chemoprevention. CA 1995;45:31-49.

19. Cuzik J, Baum M. Tamoxifen and contralateral breast cancer. Lancet 1985;2:282.

20. Early Breast Cancer Trialists Collaborative Group. Systemic treatment of early breast cancer by hormonal, cytotoxic, or immune therapy. Lancet 1992;339:1-15.

21. Tomatis, L. Ripartizione delle risorse, saggi clinici controllati e confidenzialità [Distribution of resources, controlled clinical trials and confidentiality]. In: Rodotà S, editor, Questioni di Bioetica. Bari: Laterza, 1993:28-43.

22. Boyle P. Prevention of breast cancer with Tamoxifen. Oncol $\operatorname{Pr} 1994 ; 3: 9-11$.

23. Marshall E. Tamoxifen: hanging in the balance. Science 1994;264:1524—7.

24. Williams G, Iatropoulos MJ, Djordjevic MV, Kaltenberg OP. The triphenylene drug Tamoxifen is a strong liver carcinogen in the rat. Carcinogenesis 1993;14:315-7.

25. Greaves P, Goonetilleke R, Nunn G, Topham J, Orton T. Two-year carcinogenicity study of Tamoxifen in Alderley Park Wistar-derived rats. Cancer Res 1993;53:1919 - 24 .

26. Carthew P, Martin EA, White INH, De Matteis F, Edwards RE, Dorman BM, et al. Tamoxifen induces short-term cumulative DNA damage and liver tumors in rats: promotion by phenobarbital. Cancer Res 1995;55:544-7.

27. Hard GC, Iatropoulos MJ, Jordan K, Kaltenberg OP, Imondi AR, Williams GM. Major difference in the hepatocarcinogenicity and DNA-adduct forming ability between Toremifen and Tamoxifen in female $\mathrm{Crl}: \mathrm{Cd}(\mathrm{BR})$ rats. Cancer Res 1993; $53: 4534-41$

28. Hasmann M, Rattel B, Löser R. Preclinical data for Droloxifene. Cancer Lett 1994;84:101-16.
29. International Agency for Research on Cancer (IARC). Monographs on the evaluation of carcinogenic risks to humans, vol 1-61. Lyon: IARC, 1971-1995.

30. Peto R. Smoking and death: the past 40 years and the next 40 . Br Med J 1994;309:937-9.

31. Lilienfeld DE. The silence: the asbestos industry and early occupational cancer research [case study]. Am J Public Health 1991;81:791-800.

32. Tomatis $L$. The value of long-term testing for the implementation of primary prevention. In: Hiatt HH, Watson JD, Winsten JA, editors. Origins of human cancer. Cold Spring Harbor (NY): Cold Spring Harbor Laboratory, 1977:1339—57.

33. Susser MW. Health as a human right: an epidemiologist's perspective on the public health. Am J Public Health 1993; $83: 418-26$

34. Botti C, Comba P, Forastiere F, Settimi L. Causal evaluation in environmental epidemiology: the role of implicit values. Sci Total Environ. In press.

35. Schwartz J. Air pollution and daily mortality: a review and meta analysis. Environ Res 1994;64:36-52.

36. Dockery W, Pope AC, Xu X, Spengler JD, Ware JW, Fay ME, et al. An association between air pollution and mortality in six US cities. N Engl J Med 1993; 329:1753-9.

37. Dockery W, Pope AC. Acute respiratory effect of air pollution. Ann Rey Public Health 1994;15:107-32.

38. Forastiere F, Corbo GM, Pistelli R, Michelozzi P, Agapiti N, Brancato $\mathrm{G}$, et al. Bronchial responsiveness in childen living in areas with different air pollution levels. Arch Environ Health 1994;49:111-8

39. Xu X, Li B, Huang H. Air pollution and unscheduled hospital outpatient and emergency room visits. Environ Health Perspect 1995;103:286-9.

40. Anonymous. La Santè en France. Paris: La documentation Française, 1989.

41. Anonymous. How affordable is public health? Nature (Lond) 1991;352:587-8

42. Fuchs VR. The future of health policy. Cambridge (MA): Harvard University Press, 1993.

43. Rawls J. A theory of justice. Cambridge (MA): Harvard University Press, 1971.

44. Marshall E. A new phase in the war on cancer. Science 1995; $267: 1412-4$.

Received for publication: 4 April 1995 